\title{
Perbandingan Skor DECAF dengan Skor BAP-65 terhadap Kematian dalam Tiga Puluh Hari pada Pasien PPOK Eksaserbasi Akut RSUP H. Adam Malik Medan
}

\author{
Siti Taqwa Fitria Lubis, E. N. Keliat, Alwinsyah Abidin \\ Divisi Pulmonologi dan Alergi Imunologi Departemen Ilmu Penyakit Dalam, \\ Fakultas Kedokteran Universitas Sumatera Utara/RSUP H. Adam Malik Medan
}

\begin{abstract}
Abstrak
Pada penderita penyakit paru obstruksi kronik (PPOK) eksaserbasi akut, penilaian derajat keparahan pada awal masuk penting dalam menentukan risiko kematian rawat inap rumah sakit, memutuskan perawatan bangsal atau Intensive Care Uni,t dan penatalaksanaan selanjutnya. Skor Dyspnoea, Eosinopenia, Consolidation, Acidaemia, Atrial Fibrillation (DECAF) dan skor elevated BUN, Altered mental status, pulse 109 beats/min, age >65 years (BAP-65) dapat digunakan sebagai alat prognostik. Penelitian ini bertujuan membandingkan skor DECAF dengan skor BAP65 memprediksi kematian dalam 30 hari pada pasien PPOK eksaserbasi akut. Penelitian dengan desain kohort, subjek adalah pasien PPOK eksaserbasi akut di Instalasi Gawat Darurat dan rawat inap RSUP H. Adam Malik Medan pada bulan Februari-Juni 2013. Dinilai skor DECAF dan skor BAP-65. Dihitung sensitivitas dan spesifisitas kedua skor dan dibandingkan kekuatannya. Sebanyak 40 subjek direkrut, rata-rata ( \pm SB) usia 61,07 $\pm 12,42$ tahun. Sembilan subjek (23\%) meninggal saat penelitian. Uji chi-kuadrat mendapatkan hasil signifikan skor DECAF $\mathrm{p}=0,003$ dan skor BAP-65 p=0,0026. Sensitivitas dan spesifisitas skor DECAF dan skor BAP-65, masing-masing 100\% dan 16\%, 100\%, dan 39\%. Simpulan, skor DECAF dan skor BAP-65 memiliki hubungan dengan kematian dalam 30 hari pada pasien PPOK eksaserbasi akut. Tingginya sensitivitas dan rendahnya spesifisitas menyebabkan kedua skor ini belum dapat digunakan sebagai alat prognostik. Diperlukan penelitian dengan subjek yang lebih besar untuk mendapatkan keakuratan kematian. [MKB. 2016;48(1):7-14]
\end{abstract}

Kata kunci: PPOK eksaserbasi akut, prognosis, skor BAP-65, skor DECAF

\section{Comparison between DECAF Score and BAP-65 Score in Predicting Thirty Days Mortality in Acute Exacerbations COPD Patients H. Adam Malik General Hospital}

\begin{abstract}
The assessment of severity level in patient with acute exacerbation chronic obstructive pulmonary disease (AECOPD) at early admission is important to determine the risk of in-hospital mortality, to decide hospitalization or requirement of Intensive Care Unit setting and further management. Dyspnea, eosinopenia, consolidation, acidaemia, atrial fibrillation (DECAF) score, and elevated BUN. Altered mental status, pulse 109 beats $/ \mathrm{min}$, age $>65$ years (BAP-65) can be used as prognostic tools. The aim of this study was to investigate the comparison between DECAF score and BAP-65 score in predicting 30 days-mortality in AECOPD patients. This was a cohort study, subjects were AECOPD patients in emergency unit and inpatient in H. Adam Malik General Hospital, from February to June 2013. DECAF score and BAP-65 score were assessed. We calculated sensitivity and specificity of both scores to compare the stronger predictor. Fourty subjects were recruited, mean $( \pm S D)$ age was $61.07 \pm 12.42$ years. Nine subjects (23\%) died during the study. This study presented significant result with $\mathrm{p}=0.003$ for DECAF score and $\mathrm{p}=0.0026$ for BAP- 65 score, using chi-square test. Sensitivity and specificity of DECAF score and BAP-65 score were $100 \%$ and 16\%, 100\% and 39\%, respectively. In conclusion, DECAF score and BAP-65 score have correlations with 30-days mortality in AECOPD patients. High sensitivity and low specificity prevent the use of these scores as prognostic tools. A larger study is required to determine the accuracy on mortality. [MKB. 2016;48(1):7-14]
\end{abstract}

Key words: Acute exacerbation COPD, BAP-65 score, DECAF score, prognostic

Korespondensi: Siti Taqwa Fitria Lubis, dr., Departemen Ilmu Penyakit Dalam Fakultas Kedokteran Universitas Sumatera Utara/RSUP H. Adam Malik Medan, Jalan Bunga Lau No.17 Medan, mobile 081365946984, e-mail taqwa_lubis@yahoo.co.id 


\section{Pendahuluan}

Penyakit paru obstruksi kronik (PPOK) ialah suatu penyakit paru yang dapat dicegah dan diobati, ditandai dengan hambatan aliran udara yang tidak sepenuhnya reversibel, progresif, dan berhubungan dengan respons inflamasi paru terhadap partikel atau gas yang beracun atau berbahaya. ${ }^{1,2}$

Eksaserbasi merupakan suatu kejadian utama dalam perjalanan penyakit PPOK, terutama apabila dibutuhkan perawatan rumah sakit (RS). Keadaan ini menjadi masalah karena eksaserbasi akan menyebabkan kematian rawat inap tinggi, mengganggu kualitas hidup, dan berulangnya eksaserbasi yang dapat memengaruhi perjalanan penyakit yang dinilai dari penurunan fungsi paru dan kematian., ${ }^{3,4}$

Walaupun PPOK eksaserbasi akut sering ditemukan dan dapat menjadi fatal, prognostik akurat dari pasien yang dirawat di rumah sakit dengan eksaserbasi masih sulit. ${ }^{5}$ Sulit untuk menyediakan kriteria yang sederhana dan dapat dipercaya dokter untuk mengidentifikasi pasien yang mempunyai risiko untuk kematian rawat inap RS dan membantu memutuskan apakah pasien harus dirawat inap atau tidak dan setting mana yang digunakan, perawatan di bangsal atau Intensive Care Unit (ICU). ${ }^{3}$

Studi prospektif multisenter yang dilakukan oleh Roche dkk. ${ }^{3}$ menilai hal yang menentukan hasil akhir perawatan RS pada pasien yang datang ke Instalasi Gawat Darurat (IGD) karena PPOK eksaserbasi akut. Penelitian ini menunjukkan tingkat kematian rawat inap RS adalah 7,4\%. Faktor prognostik independen adalah usia di atas 70 tahun; kombinasi memburuknya tanda klinis (sianosis, gangguan neurologis, edema tungkai bawah, astereksis, serta penggunaan otot aksesori pada saat inpirasi dan ekspirasi); dan baseline dyspnoe grade $(0-1,2-3,4-5)$ pada keadaan stabil. ${ }^{3}$

Penelitian yang dilakukan oleh Gudmundsson dkk. ${ }^{6}$ menunjukkan tingginya kematian pada pasien PPOK setelah perawatan RS, usia yang lebih tua, berkurangnya fungsi pada paru, dan status kesehatan yang menurun serta diabetes sebagai faktor risiko terpenting. Penelitian oleh Soler-Cataluna $\mathrm{dkk}^{7}$ mengelompokkan faktor prognostik yang berpengaruh pada pasien PPOK eksaserbasi akut yang mendapatkan perawatan di RS, yaitu usia pasien, merokok, indeks massa tubuh, komorbiditas, terapi oksigen jangka panjang, parameter kekuatan spirometri, dan tekanan arteri gas darah. Ternyata usia yang lebih tua dan juga tekanan karbondioksida arteri merupakan indikator prognostik buruk yang lebih baik. Studi prospektif oleh Groenewegen $\mathrm{dkk}^{8}$ menyimpulkan bahwa prognosis pasien yang datang ke rumah sakit dan memerlukan perawatan rumah sakit ialah buruk. Penggunaan kortikosteroid oral jangka panjang, $\mathrm{PaCO}_{2}$ yang tinggi, dan usia lebih tua dianggap sebagai faktor risiko yang berhubungan dengan tingginya kematian.

Holland dkk. ${ }^{9}$ melaporkan bahwa eosinopenia $\left(<0,04 \times 10^{9} / \mathrm{L}\right)$ berhubungan dengan tingginya kematian rawat inap pada PPOK eksaserbasi akut. ${ }^{10}$ Pada pasien PPOK eksaserbasi akut, eosinopenia menunjukkan keparahan yang berhubungan dengan respons inflamasi akut. ${ }^{5,11}$

Penelitian Lieberman dkk.12 mendapatkan hasil pneumonia komunitas yang paling sering dijumpai pada pasien yang dirawat di RS akibat PPOK eksaserbasi akut mempunyai manifestasi klinis dan laboratorium lebih berat, dijumpai nilai $\mathrm{PaO}_{2}$ lebih rendah, tingginya perawatan ICU, peningkatan kebutuhan ventilator mekanik, kematian, dan juga lamanya waktu rawat inap. Asidosis respitratorik kronik sekunder terjadi pada PPOK. Risiko kematian PPOK eksaserbasi akut juga berhubungan erat dengan asidosis repiratorik dan diperlukan bantuan ventilator. ${ }^{13}$

Penelitian yang dilakukan oleh Steer dkk. ${ }^{5}$ mencoba memvalidasi skor DECAF (dyspnoea, eosinopenia, consolidation, acidaemia, atrial fibrillation) dalam memprediksi kematian PPOK eksaserbasi akut di rumah sakit. Skor DECAF memiliki sensitivitas 99\% dan spesifisitas 99\% dalam menentukan kematian rawat inap dan kematian dalam 30 hari.

Penelitian yang dilakukan oleh Shorr dkk. ${ }^{14}$ memvalidasi skor BAP-65 (elevated BUN, altered mental status, pulse 109 beats/min, age $>65$ years) sebagai skor risiko untuk mengetahui tingkat keparahan PPOK eksaserbasi akut. Skor BAP65 memiliki sensitivitas $53,7 \%$ dan spesifisitas $83,6 \%$ di dalam menentukan kematian rawat inap dan kematian dalam 30 hari. Penelitian ini bertujuan membandingkan dua skor prediktor kematian, yaitu skor DECAF dan skor BAP-65 dalam menentukan kematian dalam 30 hari pada pasien PPOK eksaserbasi akut di RSUP H. Adam Malik Medan. Sensitivitas dan spesifisitas DECAF dan BAP-65 dalam rawat inap sampai saat ini belum diteliti.

\section{Metode}

Penelitian ini dilakukan dengan desain kohort, subjek adalah pasien PPOK eksaserbasi akut di 
Instalasi Gawat Darurat dan rawat inap RSUP H. Adam Malik Medan, pada bulan FebruariJuni 2013. Pasien PPOK eksaserbasi akut yang memenuhi kriteria inklusi, yaitu pria atau wanita usia di atas 40 tahun; memiliki gambaran klinis, laboratorium dan radiologis sesuai dengan PPOK eksaserbasi akut; terdapat gejala eksaserbasi pada pasien dengan riwayat PPOK sebelumnya; gejala eksaserbasi pada pasien usia di atas 40 tahun dengan riwayat merokok. Diagnosis PPOK ditegakkan berdasarkan spirometri saat dirawat di RS dan riwayat merokok di atas 10 tahun. Pasien yang berusia di bawah 40 tahun; penyakit saluran napas selain PPOK (asma berat, bronkiektasis, aspergilosis, penyakit paru interstisial); penyakit komorbiditas yang mengakibatkan menurunnya ketahanan hidup di bawah 12 bulan (metastasis malignansi); dirawat di RS oleh karena penyakit lain seperti infark miokardium, penyakit jantung kongestif, emboli paru, gagal ginjal kronik dieksklusi dari penelitian ini. Dilakukan suatu pemeriksaan laboratorium seperti darah lengkap, analisis gas darah, fungsi ginjal, albumin dan sputum, serta pemeriksaan penunjang lainnya, yaitu EKG, foto toraks, dan spirometri.

Dilakukan penilaian derajat keparahan PPOK eksaserbasi akut dengan skor DECAF dan skor BAP-65. Perhitungan skor DECAF dan skor BAP65 dari masing masing variabel dapat terlihat pada Tabel 1. Untuk skor DECAF, jika subjek memiliki skor 0-1 maka disebut risiko ringan, skor 2 disebut risiko sedang, dan jika berada pada skor $\geq 3$ disebut risiko tinggi. Untuk skor BAP-65, jika subjek berada pada kelas I maka disebut risiko ringan, kelas II-III disebut risiko sedang, dan jika berada pada kelas $\geq \mathrm{IV}$ disebut risiko tinggi.

Untuk melihat hubungan antara skor DECAF dan skor BAP-65 terhadap kematian dalam 30 hari digunakan uji chi-kuadrat dengan $\mathrm{p}<0,05$ dianggap bermakna secara statistik. Dilakukan uji diagnostik dari kedua skor untuk mencari sensitivitas, spesifisitas, positive predictive value, negative predictive value, positive likelihood ratio, negative likelihood ratio; kemudian dibandingkan kekuatannya dalam menilai kematian dalam 30 hari.

\section{Hasil}

Pada penelitian ini didapatkan 42 subjek yang memenuhi kriteria inklusi, lalu 2 di antaranya drop out karena subjek tidak dapat dihubungi. Seluruh subjek penelitian merupakan pasien rawat inap. Dijumpai 40 subjek yang memenuhi kriteria, tiga puluh (75\%) subjek berjenis kelamin pria dan sepuluh (25\%) merupakan wanita dengan usia rata-rata $( \pm S B) 61,07 \pm 12,42$ tahun. Persen prediksi forced expiratory volume 1 detik (FEV1) adalah 35,15 $\pm 12,80$, kebanyakan subjek dengan obstruksi berat. Karakteristik klinis, laboratorium, serta variabel skor DECAF dan skor BAP-65 subjek disimpulkan pada Tabel 2. Seluruh data yang telah didapat kemudian dilakukan uji chi-kuadrat untuk dapat melihat hubungan antara skor DECAF dan skor BAP-65 terhadap kematian dalam 30 hari.

Dijumpai beberapa komorbiditas penelitian

Tabel 1 Skor DECAF dan Skor BAP-65

\begin{tabular}{|c|c|c|c|}
\hline $\begin{array}{c}\text { Skor DECAF } \\
\text { Variabel }\end{array}$ & Skor & $\begin{array}{c}\text { Skor BAP-65 } \\
\text { Variabel }\end{array}$ & Kelas \\
\hline Dispnea (eMRCD)* & & Ucin $<65$ tohun tonno folotor & $\mathbf{I}$ \\
\hline eMRCD 5a & 1 & Usia $\leq 65$ tahun, tanpa faktor & 1 \\
\hline eMRCD 5b & 2 & & \\
\hline Eosinopenia $\left(<0,05 \times 10^{9} / 1\right)$ & 1 & Usia >65 tanun, tanpa raktor risiko & II \\
\hline Konsolidasi & 1 & Satu faktor risiko & III \\
\hline Asidemia $(\mathrm{pH}<7,3)$ & 1 & Dua faktor risiko & IV \\
\hline Fibrilasi atrial & 1 & Tiga faktor risiko & $\mathrm{V}$ \\
\hline Total & 6 & Total & 5 \\
\hline
\end{tabular}

Keterangan: *eMRCD: extended Medical Research Council Dyspnoea, eMRCD 5a: dapat mandi dan/atau memakai pakaian tanpa bantuan orang lain, eMRCD 5b: mandi dan memakai pakaian membutuhkan bantuan orang lain. ${ }^{* *}$ Faktor risiko: kadar BUN $\geq 25 \mathrm{mg} / \mathrm{dL}$, perubahan status mental, nadi $\geq 109 \mathrm{kali} / \mathrm{menit}$ 
Tabel 2 Data Karakteristik Dasar Subjek dengan PPOK Eksaserbasi Akut

\begin{tabular}{|c|c|}
\hline Variabel & PPOK Eksaserbasi Akut \\
\hline \multicolumn{2}{|l|}{ Jenis kelamin } \\
\hline Pria & $30(75 \%)$ \\
\hline Wanita & $10(25 \%)$ \\
\hline Usia (tahun) ( \pm SD) & $61,07 \pm 12,42$ \\
\hline \multicolumn{2}{|l|}{ Tanda vital $( \pm$ SD $)$} \\
\hline Tekanan darah sistol (mmHg) & $129,25 \pm 18,02$ \\
\hline Tekanan darah diastol (mmHg) & $79,75 \pm 11,65$ \\
\hline HR (kali/menit) & $103,17 \pm 14,49$ \\
\hline RR (kali/menit) & $30,22 \pm 3,18$ \\
\hline Temperatur (Celcius) & $37,15 \pm 0,54$ \\
\hline \multicolumn{2}{|l|}{ Laboratorium } \\
\hline $\mathrm{Hb}(\mathrm{g} / \mathrm{dL})( \pm \mathrm{SD})$ & $13,39 \pm 2,44$ \\
\hline Leukosit $\left(/ \mathrm{mm}^{3}\right)( \pm \mathrm{SD})$ & $13,23 \pm 6,59$ \\
\hline Eosinofil (x109/L) & $0,25 \pm 0,31 \times 109$ \\
\hline $\mathrm{BUN}(\mathrm{mg} / \mathrm{dL})( \pm \mathrm{SD})$ & $19,5 \pm 15,3$ \\
\hline Ureum $(\mathrm{mg} / \mathrm{dL})( \pm \mathrm{SD})$ & $41,2 \pm 32,8$ \\
\hline Kreatinin $(\mathrm{mg} / \mathrm{dL})( \pm \mathrm{SD})$ & $0,9 \pm 0,44$ \\
\hline \multicolumn{2}{|l|}{ AGDA } \\
\hline $\mathrm{pH}$ & $7,44 \pm 0,08$ \\
\hline $\mathrm{pO}_{2}$ & $119,9 \pm 41,5$ \\
\hline $\mathrm{pCO}_{2}$ & $40,5 \pm 11,2$ \\
\hline Saturasi $\mathrm{O}_{2}$ & $97,3 \pm 3,57$ \\
\hline \multicolumn{2}{|l|}{ Foto toraks } \\
\hline Normal & $18(45 \%)$ \\
\hline Konsolidasi & $20(50 \%)$ \\
\hline Efusi pleura & $1(2,5 \%)$ \\
\hline Efusi pleura+konsolidasi & $1(2,5 \%)$ \\
\hline \multicolumn{2}{|l|}{ EKG } \\
\hline Normal & $34(80 \%)$ \\
\hline Atrial fibrilasi & $2(5 \%)$ \\
\hline Hipertrofi ventrikel kanan (RVH) & $4(10 \%)$ \\
\hline \multicolumn{2}{|l|}{ FEV1 \% prediksi } \\
\hline Ringan & $0(0 \%)$ \\
\hline Sedang & $5(12 \%)$ \\
\hline Berat & $19(48 \%)$ \\
\hline Sangat berat & $16(40 \%)$ \\
\hline
\end{tabular}

Keterangan: eMRCD: extended Medical Research Council Dyspnoea, BUN: blood urea nitrogen, AGDA: analisis gas darah, FEV1: force expiratory volume 1 second, EKG: elektrokardiogram, DECAF: dyspnoea, eosinopenia, consolidation, acidaemia, atrial fibrilation. BAP-65: elevated BUN, altered mental status, nadi $>109$ kali/ menit, usia $>65$ tahun 
Tabel 3 Perbandingan Sensitivitas dan Spesifisitas Skor DECAF dan Skor BAP-65

\begin{tabular}{lcc}
\hline \multicolumn{1}{c}{ Perbandingan } & $\begin{array}{c}\text { Skor } \\
\text { DECAF }\end{array}$ & $\begin{array}{c}\text { Skor BAP- } \\
\mathbf{6 5}\end{array}$ \\
\hline Sensitivitas & $100 \%$ & $100 \%$ \\
Spesifisitas & $16 \%$ & $39 \%$ \\
Nilai duga positif & $26 \%$ & $32 \%$ \\
Nilai duga negatif & $100 \%$ & $100 \%$ \\
Rasio kemungkinan & 1,19 & 1,63 \\
positif & & \\
Rasio kemungkinan & - & - \\
negatif & & \\
\hline $\begin{array}{l}\text { DECAF: dysnoea, eosinopenia, consolidation, acidaemia, } \\
\text { atrial fibrilation; BAP-65: elevated BUN, altered mental } \\
\text { status, nadi }>109 \times / \text { min, aged }>65 \text { years }\end{array}$
\end{tabular}

ini, seperti kor pulmonal kronik, anemia, efusi pleura, hipertensi, strok iskemik, batu kandung empedu, diabetes melitus (DM) tipe 2 dan abses hati, serta dispepsia. Komorbiditas yang paling banyak dijumpai adalah kor pulmonal kronik. Semua subjek penelitian ini mendapatkan terapi standar untuk PPOK eksaserbasi akut sesuai dengan Global Initiative for Chronic Obstructive Lung Disease (GOLD) Revised 2011. Terapi untuk penyakit komorbiditas sesuai dengan standar terapi penyakit masing masing.

Tidak ditemukan subjek penelitian dengan skor DECAF di atas atau sama dengan 5, lima orang (12\%) berada pada risiko ringan, 19 orang (48\%) berada pada risiko sedang, 16 orang $(40 \%)$ berada pada risiko berat. Pada skor BAP-
65 , dijumpai tiga orang $(7 \%)$ berada pada risiko berat, 25 orang (63\%) pada risiko sedang, dan 12 orang $(30 \%)$ pada risiko ringan. Dijumpai 9 kematian pada penelitian ini. Tidak dijumpai kematian pada subjek dengan skor DECAF risiko ringan, dijumpai 1 kematian pada subjek dengan skor DECAF risiko sedang, 8 kematian pada subjek dengan skor DECAF risiko berat. Tidak dijumpai kematian pada subjek dengan BAP-65 risiko ringan, $7(17,5 \%)$ kematian pada risiko sedang, 2 (5\%) kematian pada risiko berat.

Subjek penelitian pada skor DECAF ini telah dikelompokkan menjadi 6 berdasarkan atas skor dan tidak terdapat satupun subjek yang berada pada skor 0, 5, dan 6. Hampir setengah (48\%) subjek penelitian berada pada skor 2. Skor BAP65 dikelompokkan menjadi 5 berdasarkan kelas, hanya 1 subjek yang berada pada kelas V (2\%) dan sisanya berada pada skor I-IV.

Uji chi-kuadrat digunakan untuk mengetahui hubungan antara skor DECAF dan skor BAP65 terhadap kematian dalam 30 hari. Dari uji ini telah didapatkan nilai p skor DECAF adalah $0,003(p<0,05)$ yang artinya terdapat hubungan antara skor DECAF dan kematian dalam 30 hari. Begitu juga dengan skor BAP-65, didapatkan nilai $p$ adalah $0,026(p<0,05)$, yang berarti terdapat hubungan bermakna antara skor BAP-65 dan kematian dalam 30 hari (Gambar). Dilakukan uji diagnostik, dengan menghitung sensitivitas, spesifisitas skor DECAF dan juga skor BAP-65 berdasarkan kelompok risiko (ringan, sedang, dan berat).

Berdasarkan atas data yang diperoleh pada penelitian ini, dicoba untuk mendapatkan cut-off yang baru, yaitu dengan membagi skor DECAF menjadi 2 kelompok, yaitu DECAF risiko ringan

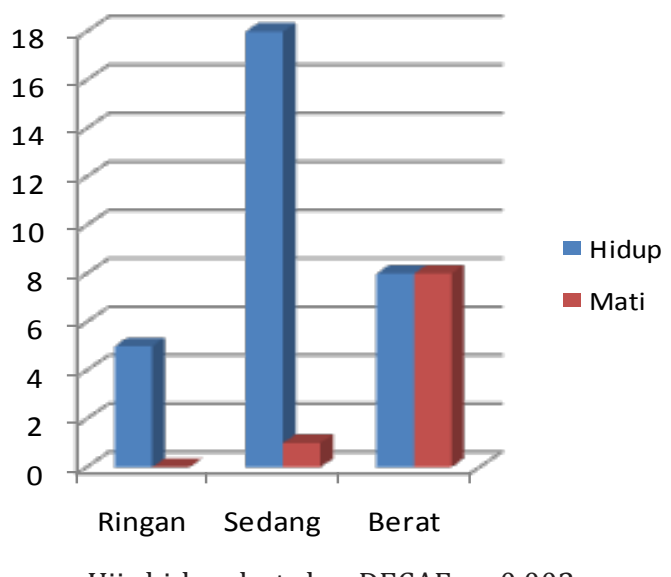

a. Uji chi-kuadrat skor DECAF $p=0,003$

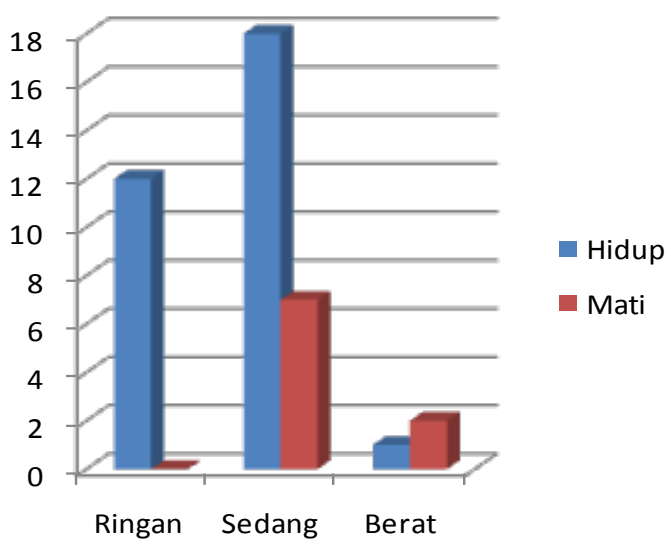

b. Uji chi-kuadrat skor BAP-65 p=0,0026

Gambar 1 Diagram Kematian dalam 30 Hari 
(skor 0-1) dengan DECAF risiko sedang dan berat (skor $\geq 2$ ) maka didapatkan sensitivitas yang tinggi 100\% dan spesifisitas rendah 16\%. Untuk skor BAP-65, juga dilakukan hal yang sama dengan membaginya menjadi 2 kelompok, yaitu BAP-65 risiko ringan (kelas I) dengan BAP-65 risiko sedang dan berat (kelas $\geq$ II) maka didapatkan sensitivitas yang tinggi 100\% dan spesifisitas rendah 39\%. Kemudian dilakukan perbandingan sensitivitas dan spesifisitas skor DECAF dengan skor BAP-65 (Tabel 3).

Keseluruhan penelitian ini dijumpai 1 subjek dengan asidosis respiratorik $(\mathrm{pH} \leq 7,3)$ dan 2 subjek $(5 \%)$ dengan gagal napas $\left(\mathrm{pO}_{2}<80\right)$ yang membutuhkan ventilator mekanik dan perawatan di ICU. Subjek yang seharusnya mendapatkan perawatan ICU hanya mendapatkan perawatan di bangsal karena ruangan ICU dalam keadaan penuh.

Dijumpai 9 (23\%) subjek meninggal saat penelitian, 7 subjek meninggal selama rawatan di RS dan 2 subjek meninggal setelah pulang dari rawatan RS. Subjek yang meninggal selama rawat inap sebagian besar diperberat karena terdapat komorbiditas. Dua subjek meninggal dengan komorbiditas kor pulmonal kronik, 2 subjek meninggal karena sepsis berat, 1 subjek meninggal komorbiditas efusi pleura dan 2 subjek dengan gagal napas. Subjek yang meninggal setelah pulang rawat inap disebabkan oleh eksaserbasi berulang karena tidak dapat mengonsumsi obat secara teratur.

\section{Pembahasan}

Penelitian oleh Steer dkk. ${ }^{5}$ memvalidasi skor DECAF dalam memprediksi kematian PPOK eksaserbasi akut di rumah sakit. Skor DECAF signifikan lebih baik dalam memprediksi kematian rawat inap dibanding dengan indeks prognosis acute phisiology and chronic health evaluation (APACHE) II, COPD and asthma physiology score, dan skor BAP-65. Skor DECAF mempunyai sensitivitas 99\% dan spesifisitas 99\% dalam menentukan kematian rawat inap dan kematian dalam 30 hari. Penelitian ini mendapatkan bahwa skor DECAF mempunyai sensitivitas yang tinggi $100 \%$, tetapi spesifisitas rendah, yaitu $16 \%$. Hal ini tidak sesuai dengan penelitian Steer dkk. ${ }^{5}$ yang menyatakan bahwa sensitivitas dan spesifisitas skor DECAF sama tingginya. Perbedaan ini mungkin disebabkan oleh jumlah sampel yang relatif sedikit dibanding dengan penelitian yang sebelumnya. Banyaknya komorbiditas yang dijumpai pada penelitian ini juga dapat memengaruhi hasil penelitian.

Penelitian yang dilakukan oleh Shorr dkk. ${ }^{14}$ memvalidasi skor BAP-65 sebagai skor risiko untuk mengetahui keparahan PPOK eksaserbasi akut. Skor BAP-65 dapat memberikan gambaran tingkat keparahan penyakit dan merupakan alat sederhana dalam mengidentifikasi pasien PPOK eksaserbasi akut terhadap risiko terjadinya efek yang merugikan. Skor BAP-65 memiliki sensitivitas $53,7 \%$ dan spesifisitas $83,6 \%$ dalam menentukan kematian rawat inap dan kematian dalam 30 hari. Penelitian ini mendapatkan skor BAP-65 memiliki sensitivitas yang tinggi 100\% dan spesifisitas rendah, yaitu 39\%. Hal ini juga tidak sesuai dengan penelitian yang sebelumnya, dengan sensitivitas pada penelitian ini lebih tinggi, tetapi spesifisitas lebih rendah. Beberapa hal yang dapat menjelaskan, di antaranya jumlah sampel yang relatif sedikit dibanding dengan penelitian sebelumnya, serta subjek penelitian kebanyakan adalah usia lanjut (geriatri) dengan berbagai komorbiditas yang dijumpai.

Penelitian yang telah dilakukan oleh Shorr dkk., ${ }^{14}$ cut-off point kelas II-V memiliki rentang sensitivitas berkisar 12-97\% serta rentang spesifisitas berkisar 18-99\%. Pada penelitian ini dilakukan uji diagnostik untuk mendapatkan cut-off kelompok risiko yang baru, yaitu dengan membagi skor DECAF menjadi 2 kelompok, yaitu DECAF risiko ringan (skor 0-1) dengan DECAF risiko sedang dan berat (skor $\geq 2$ ), hasilnya didapatkan sensitivitas yang tinggi 100\% dan spesifisitas rendah 16\%. Untuk skor BAP-65 juga dilakukan hal yang sama, dengan membaginya menjadi 2 kelompok, yaitu BAP-65 risiko ringan (kelas I) dengan BAP-65 risiko sedang dan berat (kelas $\geq \mathrm{II}$ ), didapatkan sensitivitas yang tinggi $100 \%$ dan spesifisitas rendah 39\%.

Dilakukan perbandingan antara skor DECAF dan skor BAP-65, tidak terlihat perbedaan yang nyata; pada penelitian ini telah didapatkan skor BAP-65 lebih unggul sedikit dalam spesifisitas, tetapi sama baiknya dengan skor DECAF untuk sensitivitas. Penelitian ini berbeda dengan penelitian yang dilakukan oleh Steer dkk. ${ }^{5}$ yang memperlihatkan bahwa skor DECAF lebih baik daripada skor BAP-65 secara statistik signifikan. Ada beberapa alasan yang diduga kuat dapat menyebabkan perbedaan hasil ini, yaitu jumlah sampel yang relatif kecil dibanding dengan penelitian sebelumnya, jumlah kematian yang sedikit hanya 23\% dari seluruh subjek penelitan pembagian kelas skor BAP-65 menjadi 3 (tiga) kelompok risiko agar mempermudah penelitian, dan banyaknya komorbiditas. Hal lain yang memungkinkan adalah terdapat variabel pada 
skor DECAF, yaitu extended medical research council dyspnoea (eMRCD) yang penilaiannya cenderung subjektif dibanding dengan keempat variabel lainnya yang objektif.

Studi ini memiliki beberapa keterbatasan antara lain: pertama, populasi penelitian yang kecil, hanya dilakukan pada satu rumah sakit pusat sehingga jumlah kematian juga sedikit. Kedua, populasi penelitian tidak satupun berasal dari pasien rawat di ICU, semua subjek adalah pasien yang masuk dari IGD sehingga studi ini tidak mencerminkan pasien PPOK yang dirawat di ICU. Ketiga, banyaknya komorbiditas yang dijumpai pada subjek penelitian, terutama pada usia lanjut (geriatri) menyebabkan ada faktor lain yang memperberat kematian pada PPOK eksaserbasi akut. Keempat, studi ini tidak menganalisis perbedaan kematian selama rawat inap rumah sakit dengan kematian dalam 30 hari dan tidak menganalisis berapa kali kunjungan pasien setelah rawatan rumah sakit terakhir kalinya.

Simpulan, skor DECAF dan juga skor BAP65 mempunyai hubungan bermakna terhadap kematian dalam 30 hari. Semakin tinggi skor DECAF dan skor BAP-65 maka semakin tinggi kemungkinan kematian yang disebabkan oleh PPOK ekseserbasi akut, akan tetapi rendahnya skor DECAF dan skor BAP-65 tidak mampu menyingkirkan penyebab kematian lain selain PPOK. Tinggi sensitivitas, rendah spesifisitas dari skor DECAF dan skor BAP-65 serta dijumpai berbagai keterbatasan pada penelitian ini mengakibatkan kedua skor ini masih belum dapat digunakan sebagai alat prognostik untuk menentukan kematian dalam 30 hari pada pasien PPOK eksaserbasi akut di RSUP H. Adam Malik Medan. Penelitian ini memiliki beberapa keterbatasan maka diperlukan suatu penelitian lebih lanjut dengan sampel yang lebih besar, multicenter dan penelitian yang dilakukan di ICU, serta komorbiditas yang lebih sedikit untuk mendapatkan keakuratan kematian, dan perlunya membandingkan pasien yang meninggal selama rawatan di rumah sakit dengan kematian dalam 30 hari setelah pasien pulang berobat jalan yang berdasarkan kelompok risiko.

\section{Daftar Pustaka}

1. GOLD. Global strategy for the diagnosis, management, and prevention of chronic obstructive pulmonary disease (revised 2011). 2011;2-7.

2. Riyanto B.S, Hisyam B. Obstruksi saluran pernapasan akut. Dalam: Sudoyo AW, Setiyohadi B, Alwi I, Simadibrata M, Setiati $\mathrm{S}$, penyunting. Buku ajar ilmu penyakit dalam. Edisi ke-5. Jakarta: Pusat Penerbitan Departemen Ilmu Penyakit Dalam FK UI; 2009. hlm. 2216-29.

3. Roche N, Zureik M, Soussan D, Neukirch $\mathrm{F}$, Perrotin D, the Urgence BPCO (COPD Emergency) Scientific Committee and Investigators. Predictors of outcomes in COPD exacerbation cases presenting to the emergency department. Eur Respir J. 2008; 32(4):953-61.

4. Anzueto A. Impact of exacerbations on COPD. Eur Respir Rev. 2010;19(116):113-8.

5. Steer J, Gibson J, Bourke SC. The DECAF score: predicting hospital mortality in exacerbations of chronic obstructive pulmonary disease. Thorax. 2012;67(11):970-6.

6. Gudmundsson G, Gislason T, Lindberg E, Hallin R, Ulrik CS, Brondum E, dkk. Mortality in COPD patients discharged from hospital: the role of treatment and co-morbodity. Respiratory Research. 2006;7:1-8.

7. Soler-Cataluna JJ, Martinez-Garcia MA, Sanchez PR, Selcedo E, Navarro M, Ochando R. Severe acute exacerbations and mortality in patients with chronic obstructive pulmonary disease. Thorax. 2006;60(11):925-31.

8. Groenewegen KH, Schools AMWJ, Wouters EFM. Mortality and mortality-related factors after hospitalization for acute exacerbation of COPD. Chest. 2003;124(2):459-67.

9. Holland $M$, Alkhalil $M$, Chandromouli S, Janjua A, Babores M. Eosinopenia as a marker of mortality and length of stay in patients admitted with exacerbations of chronic obstructive pulmonary disease. Respirology. 2010;15(1):165-7.

10. Steer J, Norman EM, Afolabi OA, Gibson GJ, Bourke SC. Dyspnoe severity and pneumonia as predictors of in-hospital mortality and early readmission in acute exacerbations of COPD. Thorax. 2011;67(2):117-21.

11. Abidi K, Khoudri I, Belayachi J, Madani N, Zekraoui A, Zeggwagh AA, dkk. Eosinopenia is a realible marker of sepsis on admission to medical Intensive Care Units. Crit Care. 2008;12(2):1-10.

12. Lieberman D, Lieberman D, Gelfer $Y$, Varshavsky R, Dvoskin B, Leinonen M, dkk. Pneumonic vs nonpneumonic acute exacerbations of COPD. Chest. 2002;122(4): 1264-70.

13. Shorr AF, Sun X, Johannes R, Tabak Y. Novel BAP-65 score outperforms CURB-65 score for 
Siti Taqwa: Perbandingan Skor DECAF dengan Skor BAP-65 terhadap Kematian dalam Tiga Puluh Hari pada Pasien PPOK

predicting outcomes in acute exacerbations of chronic obstructive disease. Am J Respir Crit Care Med. 2010;181:2395-8.

14. Shorr AF, Sun X, Johannes RS, Yaitanes A,
Tabak YP. Validation of novel risk score for severity of illness in acute exacerbations of COPD. Chest. 2011;140(5):1177-84. 